\title{
Análise do Programa Nacional de Alimentação Escolar (PNAE) em Passo Fundo (RS) no período de 2009 a $2017^{\text {II }}$
}

Indaia Dias Lopes ${ }^{I I I}$

Resumo: Este trabalho busca identificar como ocorreu o desenvolvimento do Programa Nacional de Alimentação Escolar (PNAE) no município de Passo Fundo, no estado do Rio Grande do Sul, a partir da implementação da Lei $n^{0} 11.947 / 2009$. Essa legislação determinou que, no mínimo $30 \%$ dos recursos destinados ao PNAE pelo Fundo Nacional de Educação (FNDE) devem ser investidos em produtos da agricultura familiar. Com a implementação da Lei $\mathrm{n}^{\circ}$ 11.947/2009 ocorreu a organização de fornecedores da agricultura familiar em Passo Fundo. Tanto por parte do órgão responsável pela alimentação escolar na prefeitura municipal, quanto dos agricultores que fornecem produtos para estes locais, decorreu um tempo para que os mesmos pudessem se adaptar e atender as exigências propostas por essa Lei. Ainda existem entraves a serem superados para aprimorar este mercado em Passo Fundo, mas é a partir da interação entre os diferentes atores sociais envolvidos com o PNAE que pode-se alcançar melhores resultados.

Palavras-chave: Alimentação escolar. Agricultura Familiar. Passo Fundo.

\section{Analysis of the National School Feeding Program (PNAE) in Passo Fundo (RS) from 2009 to 2017}

Abstract: This paper seeks to identify how the development of the National School Feeding Program (PNAE) occurred in the municipality of Passo Fundo, in the state of Rio Grande do Sul, from the implementation of Law $n^{\circ} 11.947 / 2009$. This legislation determined that at least $30 \%$ of the resources allocated to PNAE by the National Education Fund (FNDE) must be invested in family farming products. With the implementation of Law $n^{\circ} 11.947 / 2009$ the organization of family farming suppliers in Passo Fundo took place. Both the school feeding agency in the city hall, and the farmers supplying products to these places, there was a time for them to adapt and meet the requirements proposed by this Law. There are still obstacles to be overcome to improve this market in Passo Fundo, but it is from the interaction between the different social actors involved with the PNAE that the best results can be achieved.

Keywords: School feeding. Family Farming. Passo Fundo.

Artigo recebido em 13/04/2019 e aprovado em 02/06/2020. 


\section{ANÁLISE DO PROGRAMA NACIONAL DE ALIMENTAÇÃO ESCOLAR (PNAE) EM PASSO \\ FUNDO (RS) NO PERÍODO DE 2009 A 2017 \\ INDAIA DIAS LOPES}

\section{Introdução}

O Programa Nacional de Alimentação Escolar (PNAE) é um programa que objetiva, em caráter suplementar, a transferência de recursos financeiros pelo Fundo Nacional de Desenvolvimento da Educação (FNDE) aos estados, ao Distrito Federal (DF) e aos municípios, visando suprir parcialmente as necessidades nutricionais dos alunos. O PNAE, por meio da oferta de alimentos e de ações de educação alimentar e nutricional, auxilia no desenvolvimento, no crescimento, na aprendizagem, no desempenho dos alunos e contribui para a formação de hábitos alimentares saudáveis ${ }^{\mathrm{IV}}$.

A partir do ano de 2009 , com a Lei $\mathrm{n}^{\circ} 11.947$, foi regulamentado que as compras dos gêneros alimentícios para o PNAE poderiam ser realizadas por meio de um processo de compras simplificado, que são as Chamadas Públicas ${ }^{\mathrm{V}}$, permitindo que o processo licitatório fosse dispensado. Tal legislação, em seu artigo 14, determinou que, no mínimo 30\% dos recursos repassados pelo FNDE no âmbito do PNAE devem ser investidos em produtos da agricultura familiar e do empreendedor familiar rural ou de suas organizações.

O município de Passo Fundo possui 70 escolas municipais com aproximadamente 17 mil alunos ${ }^{\mathrm{VI}}$, além disso, é a maior cidade do norte do Estado do Rio Grande do Sul (RS) com uma população estimada em 198.799 habitantes ${ }^{\mathrm{VII}}$, o que justifica a escolha desse município enquanto lócus de pesquisa. Neste contexto, este trabalho tem como objetivo identificar como se desenvolveu o PNAE nas escolas municipais de Passo Fundo, especialmente a partir da vigência da Lei n ${ }^{\circ}$ 11.947/2009.

Em termos metodológicos, este estudo trata-se de uma pesquisa descritiva, com abordagem qualitativa dos dados ${ }^{\text {VIII }}$. Foram utilizadas fontes orais, legislações, documentos relativos a gestão do PNAE no nível municipal, além de livros e artigos.

Como a gestão do PNAE em Passo Fundo é centralizada na Secretaria Municipal de Educação, a processualidade metodológica desta pesquisa privilegiou entrevistas com a nutricionista do PNAE na Prefeitura, com o Secretário Municipal de Educação, diretoras de escolas e merendeiras, totalizando 15 entrevistados.

Este artigo está organizado em seis seções, a contar desta introdução. A seção dois faz uma breve contextualização da trajetória e das transformações do Programa de Alimentação Escolar (PAE) brasileiro. A seção três apresenta as formas de gestão do PNAE. Na quarta seção realiza-se uma análise da operacionalização do PNAE nas escolas municipais de Passo Fundo, especialmente a partir da vigência da Lei $\mathrm{n}^{\circ}$ 11.947/2009. Por fim, na seção cinco, apresentam-se as considerações finais, seguidas das referências.

\section{A alimentação escolar no Brasil}

O PAE teve sua origem no Brasil no início da década de 1940 em um cenário onde o Instituto de Nutrição defendia a ideia de que a alimentação escolar deveria ser financiada pelo governo federal. Na década de 1950, foi elaborado um plano denominado Conjuntura Alimentar e o Problema da Nutrição no Brasil, sendo abordada pela primeira vez a alimentação escolar em âmbito nacional sob responsabilidade pública $^{\mathrm{IX}}$.

Desde a criação do programa até o ano de 1993, a execução era realizada de forma centralizada e os gêneros alimentícios eram adquiridos via licitação (Lei $\mathrm{n}^{\mathrm{o}}$ 8.666/1993). O órgão que realizava a gestão do programa também contratava laboratórios especializados para que pudesse ser feito o controle de qualidade e era responsável por distribuir os alimentos em todo o país ${ }^{\mathrm{X}}$. 


\section{ANÁLISE DO PROGRAMA NACIONAL DE ALIMENTAÇÃO ESCOLAR (PNAE) EM PASSO \\ FUNDO (RS) NO PERÍODO DE 2009 A 2017 \\ INDAIA DIAS LOPES}

No ano de 1994, por meio da Lei $n^{\circ}$ 8.913, ocorreu a descentralização do PNAE, sendo celebrados convênios com os municípios e com o envolvimento da Secretaria de Educação dos estados e do Distrito Federal, repassando a estas a competência para atender os alunos de suas redes e das redes municipais das prefeituras que não haviam aderido à descentralização. A Medida Provisória no 1.784 de 14/12/1998 consolidou a descentralização e definiu que o repasse dos recursos para a alimentação escolar seria direto a todos os municípios e Secretarias de Educação, sem a necessidade de convênios ou instrumentos similares, facilitando o processo ${ }^{X I}$. O Fundo Nacional da Educação (FNDE), autarquia vinculada ao Ministério da Educação (MEC), é o órgão responsável pela administração do PNAE $^{\mathrm{XII}}$.

Em 2007, foram criadas parcerias entre o FNDE e as Instituições Federais de Ensino Superior brasileiras com o objetivo de constituir Centros Colaboradores em Alimentação e Nutrição do Escolar (Cecanes). Os Cecanes foram implementados no ano de 2009 em cinco Estados: na Bahia, em Brasília, no Paraná, no Rio Grande do Sul e em São Paulo. Estes centros são unidades de referência que ficam dentro das instituições de ensino superior e que desenvolvem ações direcionadas ao PNAE. Tais órgãos foram criados com o objetivo de capacitar os agentes envolvidos no programa $^{\mathrm{XIII}}$.

A Lei $n^{0} 11.947 / 2009$ instituiu seis diretrizes para a execução do PNAE: a) alimentação saudável e adequada; b) educação alimentar e nutricional; c) universalização; d) participação social; e) desenvolvimento Sustentável; f) direito à alimentação escolar. A partir destas diretrizes que o Programa é desenvolvido.

A partir de 2009, com a Lei $\mathrm{n}^{\circ} 11.947 / 2009$, foi regulamentado que as compras dos gêneros alimentícios para o PNAE poderiam ser realizadas por meio de um processo simplificado, que são as Chamadas Públicas ${ }^{\mathrm{XIV}}$, permitindo que o processo licitatório fosse dispensado.

A Lei $\mathrm{n}^{\circ} 11.947 / 2009$ propiciou a conexão entre agricultura familiar e a alimentação escolar e a construção de novos mercados pautados nos conceitos de Segurança Alimentar e Nutricional (SAN). O Brasil foi o primeiro país da América Latina que estabeleceu uma legislação regulamentando que uma porcentagem dos produtos para a alimentação escolar deveria ter origem em produtos da agricultura familiar $^{\mathrm{XV}}$.

Cabe destacar que as compras de gêneros alimentícios da agricultura familiar também podem ser realizadas por Pregão (Lei nº 8666/1993), porém, este processo não apoia o desenvolvimento sustentável, que é uma das diretrizes do PNAE. Além disso, o Pregão seleciona os fornecedores pelo critério de menor preço, enquanto a Chamada Pública não utiliza o preço como critério de seleção ${ }^{\mathrm{XVI}}$.

\section{Formas de gestão do PNAE}

Como atores do Programa constam o FNDE, as Entidades Executoras (EEx), que inclui os estados e o Distrito Federal, os municípios e as escolas federais de educação básica, as Unidades Executoras (UEx) ${ }^{\mathrm{XVII}}$ e os Conselhos de Alimentação Escolar (CAEs). O FNDE é quem faz a gestão do Programa em âmbito nacional, ficando sob sua responsabilidade a normatização, assistência financeira, coordenação, acompanhamento, monitoramento, cooperação técnica e fiscalização da execução do mesmo. As EExs, mediante o recebimento dos recursos executam o PNAE em suas respectivas redes escolares, utilizando-se das formas operacionais previstas na 


\section{ANÁLISE DO PROGRAMA NACIONAL DE ALIMENTAÇÃO ESCOLAR (PNAE) EM PASSO \\ FUNDO (RS) NO PERÍODO DE 2009 A 2017 \\ INDAIA DIAS LOPES}

legislação em vigor. Os CAEs atuam como órgão colegiado de caráter fiscalizador, permanente, deliberativo e de assessoramento do Programa ${ }^{\mathrm{XVIII}}$.

O PNAE possui uma coordenação centralizada nacionalmente no FNDE e sua execução é descentralizada através das EEx. Cada EEx responsabiliza-se pela execução do PNAE em suas respectivas redes de ensino. Mesmo o PNAE possuindo um modus operandi já bastante consolidado, sua execução é um tanto complexa, em função de envolver diversos agentes (poder público, órgãos de fiscalização e sociedade civil) nos níveis nacional, estadual e municipal.

Com relação às modalidades de gestão do PNAE, o Governo Federal, por meio do FNDE, transfere os recursos da alimentação escolar às EEx, e estas são responsáveis por definir a forma de gestão. A gestão do PNAE pode ser feita de três formas ${ }^{\text {XIX }}$ :

1. Centralizada: nesta modalidade a EEx realiza as compras e faz a distribuição dos alimentos para as escolas, esse é o modelo mais adotado nas cidades brasileiras, sendo o que está vigente nas escolas municipais de Passo Fundo;

2. Semidescentralizada: neste caso a EEx faz as compras de alguns gêneros alimentícios, distribui para as escolas, e repassa parte do recurso financeiro para que as escolas façam a aquisição dos outros tipos de alimentos. Neste modelo, em algumas cidades brasileiras as compras dos alimentos não perecíveis são feitas pela EEx e os alimentos perecíveis ou os produtos da agricultura familiar são adquiridos pelas escolas (UEx).

3. Descentralizada ou escolarizada: nesta situação a EEx recebe do FNDE os recursos e os repassa integralmente às escolas para que estas façam as aquisições dos produtos para a alimentação escolar. Este modelo escolarizado é bastante utilizado nas escolas das redes estaduais e é utilizado nas escolas estaduais de Passo Fundo.

Além das modalidades de gestão apresentadas, ainda existe a possibilidade de que a Secretaria Estadual de Educação transfira para as Prefeituras a responsabilidade pela alimentação escolar dos alunos da sua rede estadual, esta situação é denominada delegação de rede. Nos casos em que ocorre a delegação de rede, o FNDE repassa os recursos da alimentação escolar da rede estadual do município que fez esta opção diretamente para a Prefeitura Municipal ${ }^{\mathrm{XX}}$.

Os recursos para o PNAE têm origem no Tesouro Nacional e são assegurados no Orçamento Federal, no entanto, este programa possui caráter complementar, tendo os Estados e Municípios a responsabilidade pela alimentação escolar dos alunos de suas respectivas redes públicas de ensino. A complementação dos Estados e Municípios pode variar de uma localidade para outra, ou mesmo não ocorrer em alguns locais ${ }^{\mathrm{XI} I}$.

$\mathrm{O}$ valor per capita transferido pelo FNDE às Entidades Executoras (EEx) varia conforme a modalidade de ensino e contempla 200 dias letivos por ano, levando em consideração o número de alunos matriculados conforme o Censo Escolar do ano anterior ao recebimento. No Quadro 1 apresenta-se o valor per capita por dia letivo transferido pelo FNDE às EEx.

Quadro 1 - Valor per capita por dia letivo transferido pelo FNDE às EEx de acordo com a modalidade de ensino.

\begin{tabular}{|l|c|}
\hline Modalidade de ensino & Valor (R\$) per capita \\
\hline Creches & 1,07 \\
\hline Pré-escola & 0,53 \\
\hline Escolas localizadas em áreas indígenas ou de quilombolas & 0,64 \\
\hline Ensino fundamental e médio & 0,36 \\
\hline Educação de Jovens e Adultos (EJA) & 0,32 \\
\hline Programa de Fomento às Escolas de Ensino Médio em Tempo Integral & 2,00 \\
\hline
\end{tabular}


Fonte: FNDE (2019).

Os recursos são transferidos pelo FNDE às EEx em dez parcelas mensais (de fevereiro a novembro) e podem ser utilizados somente para a compra de gêneros alimentícios que serão utilizados no preparo da alimentação escolar ${ }^{\text {XII }}$.

\section{A operacionalização do PNAE nas escolas municipais de Passo Fundo}

A gestão do PNAE nas escolas municipais de Passo Fundo é centralizada na Prefeitura Municipal (EEx), por meio da Secretaria Municipal de Educação, representada pela Coordenadoria de Nutrição Escolar (CNE). Esta modalidade de gestão do PNAE é conhecida como centralizada ou municipalizada, onde as compras são centralizadas no município, neste caso na CNE, que faz as compras para todas as escolas da rede municipal. Além das escolas da rede municipal, existem oito escolas filantrópicas no município de Passo Fundo, que oferecem alimentação escolar aos seus alunos com recursos advindos do FNDE. Estes recursos são recebidos pela Secretaria Municipal de Educação que faz a gestão dos mesmos juntamente com os recursos destinados as escolas municipais. A distribuição do número de alunos na rede escolar municipal de Passo Fundo, incluindo as escolas filantrópicas que recebem recursos para o PNAE, estão organizadas no Quadro 2.

Quadro 2 - Rede escolar pública municipal de Passo Fundo, 2017.

\begin{tabular}{|l|c|c|}
\cline { 2 - 3 } \multicolumn{1}{c|}{} & $\mathbf{N}^{\mathbf{0}}$ de Escolas & $\mathbf{N}^{\mathbf{0}}$ de Alunos \\
\hline Educação Infantil & 35 & 5.158 \\
\hline Ensino Fundamental & 35 & 10.274 \\
\hline Filantrópicas & 8 & 2.085 \\
\hline Total & $\mathbf{7 8}$ & $\mathbf{1 7 . 5 1 7}$ \\
\hline
\end{tabular}

Fonte: Dados da pesquisa.

A rede escolar municipal de Passo Fundo é constituída por 70 escolas, sendo 35 Escolas Municipais de Educação Infantil (EMEI) e 35 Escolas Municipais de Ensino Fundamental (EMEF), conforme observa-se no Quadro 2.

As compras para a alimentação escolar são realizadas pela $\mathrm{CNE}$ em duas modalidades: a) Pregão eletrônico (Lei $n^{\circ}$ 8666/1993) para itens de supermercados locais, e b) Chamada Pública para itens de agricultores familiares. Destaca-se que os mecanismos de regulação dos mercados institucionais se dão por contratos públicos e regidos por legislação específica, no caso do PNAE a Lei n ${ }^{\circ} 11.947 / 2009$, o que limita a sua agilidade, porém, possibilita um maior controle para o gestor público XXIII

As compras de produtos para a alimentação escolar da rede municipal de Passo Fundo até o ano de 2009 eram realizadas em sua totalidade por meio de Licitação (Lei $n^{0}$ 8.666/1993), levando em consideração o menor preço. Quando a Lei no 11.947/2009 passou a vigorar não existia ainda fornecedores da agricultura familiar organizados no município de Passo Fundo para abastecer a alimentação escolar, dessa forma, a CNE precisou identificar se no município havia agricultores familiares individuais ou organizados em cooperativas que pudessem suprir este mercado.

A Chamada Pública é elaborada pela CNE com a Coordenadoria de Licitação e Contratos (CLC) da Prefeitura Municipal e envolve diferentes etapas, conforme pode-se visualizar na Figura 1.

Figura 1- Etapas para a elaboração da Chamada Pública nas escolas municipais de Passo Fundo. 
ANÁLISE DO PROGRAMA NACIONAL DE ALIMENTAÇÃO ESCOLAR (PNAE) EM PASSO

FUNDO (RS) NO PERÍODO DE 2009 A 2017

INDAIA DIAS LOPES

\begin{tabular}{|c|}
\hline -Verificar os recursos (FNDE e municipais) que serão disponibilizados para o ano em questão; \\
\hline -Dividir os alimentos conforme a quantidade per capita e a sazonalidade da produção; \\
\hline $\begin{array}{l}\text { - Fazer a pesquisa de preço dos alimentos na Feira do Produtor, nos mercados locais e nas } \\
\text { cooperativas de agricultores familiares e, a partir destes preços, compor o preço médio que será } \\
\text { divulgado no edital; }\end{array}$ \\
\hline $\begin{array}{l}\text { - Após a etapa de elaboração do edital de Chamada Pública o mesmo é divulgado na imprensa } \\
\text { local e na Prefeitura Municipal de Passo Fundo; }\end{array}$ \\
\hline $\begin{array}{l}\text { - Recebimento e seleção dos Projetos de Venda encaminhados pelos agricultores familiares ou } \\
\text { pelas Cooperativas de Agricultores; }\end{array}$ \\
\hline - Classificação dos fornecedores selecionados e assinatura dos contratos na CLC; \\
\hline • Elaboração do cronograma de entregas pela CNE e envio dos mesmos aos fornecedores; \\
\hline $\begin{array}{l}\text { - Entrega dos produtos nas escolas ou na CNE e, após a conferência é emitida a Nota Fiscal e } \\
\text { finalizada a Chamada Pública. }\end{array}$ \\
\hline
\end{tabular}

Fonte: Dados da pesquisa.

A primeira etapa da elaboração da Chamada Pública envolve a verificação dos recursos que serão destinados pelo FNDE e dos recursos destinados pela Prefeitura Municipal para a compra dos gêneros alimentícios. Procede-se, então, ao levantamento do número de alunos e da divisão dos alimentos per capita, levando em consideração a sazonalidade da produção. Na terceira etapa realiza-se uma pesquisa de preços a fim de compor o preço de aquisição, que deve constar no edital. A quarta etapa envolve a divulgação do edital de Chamada Pública na imprensa local e na Prefeitura Municipal. $\mathrm{Na}$ quinta etapa são recebidos e selecionados os Projetos de Venda dos agricultores familiares e das associações ou cooperativas, seguidas da classificação e posterior assinatura dos contratos. Após é elaborado o cronograma de entrega pela CNE e enviado aos fornecedores e, por fim, é feita a entrega dos produtos e emitida a nota fiscal. Todos os pagamentos são realizados pelo setor de finanças da Secretaria da Fazenda Municipal.

Os itens não perecíveis são entregues pelos vencedores das licitações diretamente no depósito da CNE, os itens perecíveis, tais como hortifrutigranjeiros e panificados são entregues pelos fornecedores (agricultores, associações ou cooperativas familiares) diretamente nas escolas, com periodicidade semanal ou conforme a necessidade da escola. A CNE possui caminhão próprio para fazer a entrega dos produtos nas escolas, tendo este veículo uma parte com refrigeração, própria para o transporte de alimentos, como carnes, lácteos.

A CNE possui sede própria e separada das instalações da Prefeitura Municipal. Neste local ficam lotados os funcionários que desempenham atividades relacionadas à alimentação escolar: duas nutricionistas, sendo uma delas a Coordenadora de Nutrição Escolar e Nutricionista Responsável Técnica (RT) pelo PNAE, uma funcionária 


\section{ANÁLISE DO PROGRAMA NACIONAL DE ALIMENTAÇÃO ESCOLAR (PNAE) EM PASSO \\ FUNDO (RS) NO PERÍODO DE 2009 A 2017 \\ INDAIA DIAS LOPES}

responsável por encaminhar os alimentos para as escolas, uma funcionária responsável por controlar os alimentos do estoque, um menor aprendiz, três motoristas (terceirizados) para realizar as entregas nas escolas e uma servente responsável pela limpeza do setor. A atuação do profissional nutricionista é fundamental para a execução do PNAE, sendo que este profissional tem a competência de realizar atividades de planejamento, coordenação, direção, supervisão e avaliação de todas as ações de alimentação e nutrição no âmbito da alimentação escolar XXIV

Quanto à origem dos recursos financeiros, o FNDE faz o repasse dos valores em dez parcelas ao ano para a cobertura de 200 dias letivos ${ }^{\mathrm{XV}}$ e é realizada uma complementação XXVI com recursos financeiros da Prefeitura Municipal. Esta complementação é realizada somente para as escolas municipais, as escolas filantrópicas recebem somente os alimentos adquiridos com recursos advindos do FNDE.

De 2009 até 2011 não foram realizadas Chamadas Públicas para a agricultura familiar e o processo de compra destes fornecedores era feito por Licitação. As Chamadas Públicas começaram a ser realizadas somente em 2012. Até o ano de 2011 inclusive as compras que foram realizadas de agricultores familiares utilizaram a Licitação como instrumento de compra.

Com a inserção da atual nutricionista da CNE, no final do ano de 2012, identificou-se diversos problemas com os fornecedores da agricultura familiar, tais como: entrega de alimentos diferentes aos solicitados, embalagens inadequadas, dentre outros. Para participar da Chamada Pública as cooperativas de agricultores familiares apresentavam alimentos de boa qualidade nas amostras, mas nas escolas eram entregues produtos com outro padrão de qualidade.

Para que fosse possível construir um diálogo com fornecedores da agricultura familiar visando qualificar a alimentação escolar e cumprir o disposto no artigo 14 da Lei $\mathrm{n}^{\mathrm{o}} 11.947 / 2009$ foi necessário criar relações e parcerias com duas importantes instituições. Primeira, a Unidade de Cooperativismo ${ }^{\text {XXVII }}$ (UCP) da Emater de Erechim, apresentada enquanto articuladora entre as cooperativas de agricultores familiares e as escolas estaduais na seção anterior. A UCP da Emater atua com as Cooperativas de agricultores familiares auxiliando na documentação, legislação, alvará sanitário, na organização de produção, dentre outras atividades. Segunda, o Escritório municipal da Emater de Passo Fundo, atuando diretamente com os agricultores familiares, auxiliando com a realização de oficinas, tais como: para formação de preços para os produtos, preparação de bolachas, instruções sobre a elaboração de embalagens, dentre outras necessidades.

Com a participação da UCP da Emater de Erechim, a partir de 2013, foi desenvolvido um trabalho de sensibilização e motivação entre os atores sociais envolvidos com a alimentação escolar na rede municipal a favor de adquirir produtos de agricultores familiares. Estavam envolvidos: o secretário de educação, as nutricionistas do programa, a Emater, o CAE, o Conselho Municipal de Segurança Alimentar (Comsea) e cooperativas de agricultores familiares, dentre outros.

Realizou-se reuniões de articulação entre os representantes dos referidos órgãos com vistas a buscar mútuos entendimentos acerca da legislação, a fim de construir um diálogo entre esses diferentes atores envolvidos direta ou indiretamente com a alimentação escolar, identificando as dificuldades existentes tanto do lado da oferta quanto da demanda e criando estratégias para superar os problemas e aprimorar o processo de comercialização. 


\section{ANÁLISE DO PROGRAMA NACIONAL DE ALIMENTAÇÃO ESCOLAR (PNAE) EM PASSO \\ FUNDO (RS) NO PERÍODO DE 2009 A 2017 \\ INDAIA DIAS LOPES}

Quando iniciado este trabalho de aproximação entre a Emater e a CNE, no ano de 2013, havia quatro organizações da agricultura familiar, fornecendo alimentos para a rede municipal. Ao final de 2015, contava com 11 organizações, resultando na inclusão de novas cooperativas da agricultura familiar, oportunizando o acesso ao mercado por atores sociais até então excluídos e também, possibilitando ofertar uma maior diversidade de produtos.

A obrigatoriedade prevista em Lei de adquirir um percentual mínimo em produtos de agricultores familiares (30\% dos repasses do FNDE) traz consigo benefícios, mas também dificuldades para os atores sociais envolvidos. Benefícios porque possibilita que sejam adquiridos gêneros alimentícios de agricultores locais e isto contribui para fomentar a economia local. No entanto, com a referida Lei a CNE defrontou-se com um "despreparo" por parte dos agricultores familiares locais para participar do mercado gerado pela alimentação escolar.

Dentre as principais dificuldades enfrentadas a partir de 2013 na operacionalização do PNAE em relação às compras da agricultura familiar no âmbito da rede escolar municipal, a CNE destacou: exigências sanitárias (alvarás), padronização na rotulagem dos produtos, falta de conhecimento do agricultor sobre comercialização e capacidade de organização do agricultor (formação de preços) e logística de entrega.

Do ponto de vista sanitário, alguns agricultores familiares precisaram regularizar suas agroindústrias e obter os alvarás sanitários que os possibilitassem participar das Chamadas Públicas. Salienta-se que muitos desses agricultores familiares, mesmo vinculados a cooperativas, possuem limitados conhecimentos acerca da comercialização, e a exigência de alvarás se constitui em uma das dificuldades enfrentadas pela CNE. Muitos agricultores e pequenas cooperativas participavam das Chamadas Públicas, mas sendo os alvarás uma exigência, muitas vezes acabavam desclassificadas.

A legislação sanitária é percebida como uma dificuldade enfrentada também pelos agricultores familiares no Brasil, mais especificamente no que se refere a produtos pecuários. Por exemplo, no caso de leite e carne, o processamento deve ocorrer em laticínios e frigoríficos, os quais, em geral, possuem plantas de grande porte ${ }^{\mathrm{XXVIII}}$. A exigência de alvará sanitário se constitui em uma garantia para as prefeituras de que os fornecedores são empresas confiáveis e de que os produtos adquiridos são de qualidade. Porém, estas exigências também podem ser uma barreira para os agricultores familiares devido ao custo financeiro. XXIX

A rotulagem também é outra dificuldade destacada pela CNE. Alguns produtos; tais como pães, bolachas, cucas, em especial das agroindústrias, eram entregues em embalagens sem padronização, com datas de validade escritas a caneta. Em prol de melhorias nas condições das embalagens dos produtos, os extensionistas da Emater municipal realizaram oficinas sobre rotulagem de alimentos da agricultura familiar. As oficinas possibilitam qualificar os produtos destes agricultores familiares para que eles possuam um padrão de apresentação.

A logística também é uma das dificuldades apontadas pela CNE, pois os produtos perecíveis tais como frutas, verduras e legumes são entregues pelos fornecedores em cada uma das 70 escolas, já os produtos não perecíveis como arroz, feijão, leite em pó, massa, sucos e as carnes são entregues no depósito da CNE.

A entrega em um número muito grande de escolas é considerada pela CNE como uma barreira para a participação de agricultores familiares. Nesse sentido ${ }^{\mathrm{XXX}}$, muitos agricultores comercializam produtos frescos e a entrega em cada escola, conforme é 


\section{ANÁLISE DO PROGRAMA NACIONAL DE ALIMENTAÇÃO ESCOLAR (PNAE) EM PASSO \\ FUNDO (RS) NO PERÍODO DE 2009 A 2017 \\ INDAIA DIAS LOPES}

exigido nas Chamadas Públicas torna-se inviável financeiramente para esses fornecedores.

As dificuldades destacadas vêm sendo superadas a partir da atuação da Emater municipal, auxiliando diretamente com os agricultores familiares e da UCP da Emater de Erechim, atuando com as cooperativas, além de todo o empenho da CNE. O relacionamento entre os diferentes órgãos vem possibilitando melhores resultados.

Para o secretário de educação municipal, em Passo Fundo o apoio da Emater foi fundamental para entender a capacidade de produção dos agricultores familiares fornecedores para o PNAE, bem como a área de plantio e o tempo para produzir os alimentos a serem demandados para a alimentação escolar. Estes entendimentos entre os atores sociais envolvidos na comercialização do Programa são essenciais a fim de estabelecer as relações de parcerias entre a CNE e os agricultores.

A função das escolas municipais na operacionalização do PNAE inicia a partir do recebimento dos gêneros alimentícios adquiridos pela CNE. As diretoras das escolas e as merendeiras conferem os alimentos recebidos e, caso os mesmos não estejam de acordo com o padrão de qualidade exigido pela CNE, ocorre a devolução.

Todas as escolas da rede municipal possuem cozinha, onde a alimentação escolar é preparada e refeitório para que os alunos façam as refeições. Os cardápios para as escolas municipais são elaborados pelas nutricionistas da CNE, respeitando os hábitos alimentares locais e culturais, atendendo as necessidades nutricionais específicas conforme percentuais mínimos estabelecidos no artigo 14 da Resolução ${ }^{\circ}$ 26/2013 XXXI . Para as merendeiras entrevistadas, o cardápio é adaptado à realidade local e a alimentação escolar é preparada de acordo com as indicações de refeições nele previstas. Quando não disponibilizam de ingredientes ou alimentos necessários para seguir o cardápio, há a possibilidade de fazer substituição de alimentos, preservando a indicação nutricional de cada refeição.

Em relação às refeições oferecidas, em geral, tanto as diretoras de escolas quanto as merendeiras declaram dificuldades de aceitação de frutas e verduras por alguns alunos, mas percebem que são hábitos alimentares oriundos do ambiente familiar. A escola enquanto instituição procura estimular bons hábitos alimentares, explicando a importância de uma alimentação mais saudável, realizando atividades com alimentos e também inserindo novos alimentos.

As merendeiras das escolas municipais participam anualmente de dois treinamentos, os quais são promovidos pela CNE, juntamente com seus parceiros (CAE, Emater, Comsea e cooperativas de agricultores familiares). O papel desempenhado por essas funcionárias na preparação dos alimentos para os alunos, visando a aceitação dos alimentos pelos mesmos, é previsto nos treinamentos, cujo objetivo é de orientar a manipulação e a preparação dos alimentos, a forma como devem ser oferecidos, o modo de armazenamento, cuidados com prazo de validade, a inserção de novos produtos, além de qualificar o trabalho desempenhado por essas funcionárias.

A partir da pesquisa de campo realizada nas escolas municipais, identificou-se ambientes organizados, controle de alimentos tanto em termos de qualidade, quanto de quantidade. As diretoras, coordenadoras e merendeiras participam dos eventos e treinamentos promovidos pela $\mathrm{CNE}$, contribuindo para a discussão e para o aprimoramento do PNAE. Em geral, as gestoras das escolas municipais mostraram-se satisfeitas com o trabalho que vem sendo desenvolvido no município de Passo Fundo a partir de 2013, com foco na aquisição de alimentos provenientes de agricultores familiares, priorizando a qualidade dos produtos e estimulando hábitos alimentares 


\section{ANÁLISE DO PROGRAMA NACIONAL DE ALIMENTAÇÃO ESCOLAR (PNAE) EM PASSO \\ FUNDO (RS) NO PERÍODO DE 2009 A 2017 \\ INDAIA DIAS LOPES}

saudáveis aos alunos. A dedicação, o empenho e a organização percebidos nos representantes da CNE, na secretaria de educação, nos conselhos locais e na Emater têm reflexos no dia-a-dia das escolas e, principalmente, na informação que chega aos alunos junto com o alimento recebido.

\section{Considerações finais}

Em Passo Fundo, na rede municipal de ensino a gestão do PNAE é centralizada na Prefeitura Municipal, modalidade conhecida como centralizada ou municipalizada. Este município possui 70 escolas municipais, sendo 35 escolas de educação infantil e 35 escolas de ensino fundamental. Até o ano de 2009 as compras para a alimentação escolar em Passo Fundo eram realizadas somente por licitação e não eram adquiridos produtos de agricultores familiares. A partir da implementação da referida legislação ocorreu um processo de constituição deste mercado institucional em Passo Fundo, com a organização de fornecedores da agricultura familiar buscando integrar este mercado. Tanto por parte do órgão responsável pela alimentação escolar na prefeitura municipal, quanto dos agricultores que fornecem produtos para estes locais, decorreu um tempo para que os mesmos pudessem se adaptar e atender as exigências propostas pela Lei $\mathrm{n}^{\mathbf{0}}$ 11.947.

A Emater é uma instituição que vem atuando neste processo, auxiliando os agricultores e suas organizações cooperativas, os gestores do PNAE na Prefeitura Municipal e também junto às escolas.

Considera-se que ainda existem dificuldades e entraves a serem superados para aprimorar este mercado em Passo Fundo, mas é a partir da interação entre os diferentes atores sociais envolvidos com o PNAE que se pode alcançar melhores resultados.

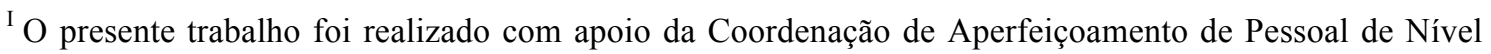
Superior - Brasil (CAPES) - Código de Financiamento 001.

${ }^{\text {II }}$ Este trabalho foi apresentado no $1^{\circ}$ Encontro de Pesquisadores da História de Passo Fundo, realizado no Instituto Histórico de Passo Fundo, nos dias 06 e 07 de junho de 2019. Após os ajustes sugeridos pelos avaliadores, foi elaborada esta versão apresentada à Revista Cadernos do Tempo Presente.

III Doutoranda em História no Programa de Pós Graduação em História da Universidade de Passo Fundo (PPGH/UPF); Bolsista Prosuc/Capes; Editora da Revista Semina (ISSN: 1677-1001).

IV FNDE. Fundo Nacional de Desenvolvimento da Educação. Cartilha Nacional da Alimentação Escolar. Brasília: 2015.

${ }^{V}$ FNDE. Fundo Nacional de Desenvolvimento da Educação. Programa Nacional de Alimentação Escolar. Histórico. Disponível em:

$<$ http://www.fnde.gov.br/programas/pnae/pnae-sobre-o-programa/pnae-historico>. Acesso em: 17 nov. 2016a.

${ }^{V I}$ FNDE. Fundo Nacional de Desenvolvimento da Educação. Alunado por ação do Programa Nacional de Alimentação Escolar. Disponível em:

$<$ http://www.fnde.gov.br/pnaeweb/publico/relatorioDelegacaoEstadual.do>. Acesso em: 20 dez. 2017.

VII IBGE. Instituto Brasileiro de Geografia e Estatística. Passo Fundo. Cidades. Passo Fundo. Disponível em: < https://cidades.ibge.gov.br/brasil/rs/passo-fundo/panorama>. Acesso em: 10 dez. 2017.

VIII GIL, Antônio Carlos. Métodos e técnicas de pesquisa social. São Paulo: Atlas, 2016.

IX FNDE. Fundo Nacional de Desenvolvimento da Educação. Programa Nacional de Alimentação Escolar. Histórico. Disponível em:

$<$ http://www.fnde.gov.br/programas/pnae/pnae-sobre-o-programa/pnae-historico $>$. Acesso em: 17 nov. 2016 a.

${ }^{\mathrm{X}}$ FNDE. Fundo Nacional de Desenvolvimento da Educação. Programa Nacional de Alimentação

Escolar. Histórico. Disponível em:

$<$ http://www.fnde.gov.br/programas/pnae/pnae-sobre-o-programa/pnae-historico $>$. Acesso em: 17 nov. 2016a.
} 


\section{ANÁLISE DO PROGRAMA NACIONAL DE ALIMENTAÇÃO ESCOLAR (PNAE) EM PASSO FUNDO (RS) NO PERÍODO DE 2009 A 2017 INDAIA DIAS LOPES}

\footnotetext{
${ }^{\mathrm{XI}}$ FNDE. Fundo Nacional de Desenvolvimento da Educação. Programa Nacional de Alimentação Escolar. Histórico. Disponível em:

$<$ http://www.fnde.gov.br/programas/pnae/pnae-sobre-o-programa/pnae-historico>. Acesso em: 17 nov. $2016 \mathrm{a}$.

XII PEIXINHO, Albaneide; et al. Alimentação Escolar no Brasil e nos Estados Unidos. $O$ mundo da saúde, v. 35, n. 2, p. 128-136. 2011.

${ }^{X I I I}$ FNDE. Fundo Nacional de Desenvolvimento da Educação. Aquisição de produtos da agricultura familiar para a alimentação escolar. $2^{\mathrm{a}}$ edição - versão atualizada com a Resolução CD/FNDE ${ }^{\circ}$ 04/2015. Disponível em: <http://www.fnde.gov.br/centrais-de-conteudos/publicacoes/category/116alimentacao-escolar?download=9815:pnae-manual-aquisicao-de-produtos-da-agricultura-familiar-para-aalimentacao-escolar-2-edicao>. Acesso em: 01 dez. 2016 b.

${ }^{\text {XIV }}$ FNDE. Fundo Nacional de Desenvolvimento da Educação. Aquisição de produtos da agricultura familiar para a alimentação escolar. $2^{\mathrm{a}}$ edição - versão atualizada com a Resolução CD/FNDE ${ }^{\circ}$ 04/2015. Disponível em: <http://www.fnde.gov.br/centrais-de-conteudos/publicacoes/category/116alimentacao-escolar?download=9815:pnae-manual-aquisicao-de-produtos-da-agricultura-familiar-para-aalimentacao-escolar-2-edicao>. Acesso em: $01 \mathrm{dez} .2016 \mathrm{~b}$.

XV (FAO; OPAS, 2017)

${ }^{X V I}$ FNDE. Fundo Nacional de Desenvolvimento da Educação. Aquisição de produtos da agricultura familiar para a alimentação escolar. $2^{\mathrm{a}}$ edição - versão atualizada com a Resolução CD/FNDE ${ }^{\circ}$ 04/2015. Disponível em: <http://www.fnde.gov.br/centrais-de-conteudos/publicacoes/category/116alimentacao-escolar?download=9815:pnae-manual-aquisicao-de-produtos-da-agricultura-familiar-para-aalimentacao-escolar-2-edicao>. Acesso em: 01 dez. 2016 b.

XVII Entidade privada formalmente constituída e sem fins lucrativos, representativa da comunidade escolar (Caixa Escolar, Associação de Pais e Mestres ou similar), responsável pelo recebimento dos recursos financeiros transferidos pela Entidade Executora, bem como pela prestação de contas à mesma (FNDE, 2013).
}

XVIII (BRASIL, 2009; FNDE, 2013)

${ }^{\mathrm{XIX}}$ TCU. Tribunal de Contas da União. Cartilha para conselheiros do Programa Nacional de Alimentação Escolar (PNAE). Brasília: TCU, 2017.

${ }^{\mathrm{XX}}$ TCU. Tribunal de Contas da União. Cartilha para conselheiros do Programa Nacional de Alimentação Escolar (PNAE). Brasília: TCU, 2017.

XXI PEIXINHO, Albaneide; et al. Alimentação Escolar no Brasil e nos Estados Unidos. O mundo da saúde, v. 35, n. 2, p. 128-136. 2011.

XXII FNDE. Fundo Nacional de Desenvolvimento da Educação. Cartilha Nacional da Alimentação Escolar. Brasília: 2015.

XXIII SCHNEIDER, Sergio. Mercados e agricultura familiar. In:MARQUES, Flávia Charão.;

CONTERATO, Marcelo Antônio; SCHNEIDER, Sergio. Construção de mercados e agricultura familiar: desafios para o desenvolvimento rural. Porto Alegre: UFRGS, 2016, p. 93-140.

XXIV TCU. Tribunal de Contas da União. Cartilha para conselheiros do Programa Nacional de Alimentação Escolar (PNAE). Brasília: TCU, 2017.

XXV FNDE. Fundo Nacional de Desenvolvimento da Educação. Cartilha Nacional da Alimentação Escolar. Brasília: 2015.

${ }^{X X V I}$ A complementação financeira realizada pela Prefeitura Municipal de Passo Fundo varia de um ano para o outro, tendo chegado em 2016 a quase duas vezes o valor repassado pelo FNDE.

XXVII Desde o ano de 2011, a Emater/RS possui sete Unidades de Cooperativismo (UCP) no RS, as quais foram implementadas pelo Programa de Apoio ao Desenvolvimento do Cooperativismo Gaúcho. A UCP da Emater de Erechim atua em 72 municípios nas regiões administrativas de Erechim e Passo Fundo, no RS, buscando melhorias técnico-gerenciais para cooperativas, contemplando agricultores familiares associados (ALBRECHT et al., 2015).

XXVIII TRICHES, Rozane Márcia; BACCARIN, José Giácomo. Interações entre alimentação escolar e agricultura familiar para o desenvolvimento local. In: TEO, Carla Rosane Paz Arruda; TRICHES, Rozane Márcia. (Orgs.). Alimentação escolar: construindo interfaces entre saúde, educação e desenvolvimento. Chapecó: Unochapecó, 2016, p, 89-109.

XXIX BELIK, Walter. Os limites para a expansão dos mercados locais. In: MARQUES, F. C.; CONTERATO, M. A.; SCHNEIDER, Sergio (Orgs.). Construção de mercados e agricultura familiar: desafios para o desenvolvimento rural. Porto Alegre: UFRGS, 2016, p. 183 - 205. 
Xxx BELIK, Walter. Os limites para a expansão dos mercados locais. In: MARQUES, F. C.; CONTERATO, M. A.; SCHNEIDER, Sergio (Orgs.). Construção de mercados e agricultura familiar: desafios para o desenvolvimento rural. Porto Alegre: UFRGS, 2016, p. 183 - 205.

${ }_{\text {XXXI }}$ FNDE. Fundo Nacional de Desenvolvimento da Educação. Resolução CD/FNDE $n^{\circ} 26$ de 17 de junho de 2013. Dispõe sobre o atendimento da alimentação escolar aos alunos da educação básica no âmbito do PNAE. Diário Oficial [da] União, Brasília, DF, 14 jun. 2013.

\section{Referências}

ALBRECHT, Angélica. Leoni; et al. A dinâmica de ATERS na efetivação do PNAE no município de Passo Fundo/RS. Disponível em:

$<$ http://www.mda.gov.br/sitemda/sites/sitemda/files/user_img_1035/Oficial\%20Emater \%20RS\%20\%28mercados\%20institucionais\%29_0.pdf>. Acesso em: 05 jun. 2017.

BELIK, Walter. Os limites para a expansão dos mercados locais. In: MARQUES, F. C.; CONTERATO, M. A.; SCHNEIDER, Sergio (Orgs.). Construção de mercados e agricultura familiar: desafios para o desenvolvimento rural. Porto Alegre: UFRGS, 2016, p. $183-205$.

BRASIL. Lei $n^{\circ} 11.947$, de 16 de junho de 2009. Dispõe sobre o atendimento da alimentação escolar e do programa dinheiro direto na escola aos alunos da educação básica, altera a lei ${ }^{\circ} 10.880$, de 9 de junho de 2004, 11.273, de 6 de fevereiro de 2006, 11.507, de 20 de julho de 2007; revoga dispositivos da Medida Provisória no 2.178-36, de 24 de agosto de 2001, e a Lei 8.913, de 12 de julho de 1994; e dá outras providências. Diário Oficial [da] União. 2009.

FAO; OPAS. Organización de las Naciones Unidas para La Alimentación y La Agricultura; Organización Panamericana de La Salud. América Latina y el Caribe. Panorama de la seguridad alimentaria y nutricional. Sistemas alimentarios sostenibles para poner fin al hambre y la malnutrición. Santiago, 2017.

FNDE. Fundo Nacional de Desenvolvimento da Educação. Resolução $C D / F N D E n^{\circ} 26$ de 17 de junho de 2013. Dispõe sobre o atendimento da alimentação escolar aos alunos da educação básica no âmbito do PNAE. Diário Oficial [da] União, Brasília, DF, 14 jun. 2013.

FNDE. Fundo Nacional de Desenvolvimento da Educação. Cartilha Nacional da Alimentação Escolar. Brasília: 2015.

FNDE. Fundo Nacional de Desenvolvimento da Educação. Programa Nacional de Alimentação Escolar. Histórico. Disponível em:

$<$ http://www.fnde.gov.br/programas/pnae/pnae-sobre-o-programa/pnae-historico $>$. Acesso em: 17 nov. 2016a.

FNDE. Fundo Nacional de Desenvolvimento da Educação. Aquisição de produtos da agricultura familiar para a alimentação escolar. $2^{\mathrm{a}}$ edição - versão atualizada com a Resolução CD/FNDE no 04/2015. Disponível em: <http://www.fnde.gov.br/centrais-deconteudos/publicacoes/category/116-alimentacao-escolar?download=9815:pnae- 
manual-aquisicao-de-produtos-da-agricultura-familiar-para-a-alimentacao-escolar-2edicao >. Acesso em: 01 dez. 2016b.

FNDE. Fundo Nacional de Desenvolvimento da Educação. Alunado por ação do Programa Nacional de Alimentação Escolar. Disponível em:

$<$ http://www.fnde.gov.br/pnaeweb/publico/relatorioDelegacaoEstadual.do $>$. Acesso em: 20 dez. 2017.

FNDE. Fundo Nacional de Desenvolvimento da Educação. Sobre o PNAE. Disponível em:

$<$ https://www.fnde.gov.br/index.php/programas/pnae> . Acesso em: 05 set. 2019.

GIL, Antônio Carlos. Métodos e técnicas de pesquisa social. São Paulo: Atlas, 2016.

IBGE. Instituto Brasileiro de Geografia e Estatística. Passo Fundo. Cidades. Passo Fundo. Disponível em: < https://cidades.ibge.gov.br/brasil/rs/passo-fundo/panorama $>$. Acesso em: 10 dez. 2017.

PEIXINHO, Albaneide; et al. Alimentação Escolar no Brasil e nos Estados Unidos. $O$ mundo da saúde, v. 35, n. 2, p. 128-136. 2011.

SCHNEIDER, Sergio. Mercados e agricultura familiar. In:MARQUES, Flávia Charão.; CONTERATO, Marcelo Antônio; SCHNEIDER, Sergio. Construção de mercados e agricultura familiar: desafios para o desenvolvimento rural. Porto Alegre: UFRGS, 2016, p. 93-140.

SOARES, Fábio Veras; et al. Demanda estruturada e a agricultura familiar no Brasil: o caso do PAA e do PNAE. Brasília: IPC-IG/WFP, 2013.

TCU. Tribunal de Contas da União. Cartilha para conselheiros do Programa Nacional de Alimentação Escolar (PNAE). Brasília: TCU, 2017.

TRICHES, Rozane Márcia; BACCARIN, José Giácomo. Interações entre alimentação escolar e agricultura familiar para o desenvolvimento local. In: TEO, Carla Rosane Paz Arruda; TRICHES, Rozane Márcia. (Orgs.). Alimentação escolar: construindo interfaces entre saúde, educação e desenvolvimento. Chapecó: Unochapecó, 2016, p, 89-109. 